\title{
A New Project dedicated to developing International MOBILity of APPrentices in the Master's Degree in Instrumentation, Measurement and Metrology (MOBIL-APP project)
}

\author{
C. Reynard-Carette \\ ${ }^{1}$ Aix Marseille Univ, Université de Toulon, CNRS, IM2NP, Marseille, France \\ christelle.carette@univ-amu.fr
}

\begin{abstract}
The project concerns the outgoing international mobility of block-release apprentices preparing the Master's degree in Instrumentation, Measurement, Metrology of the Filière Instrumentation (Physics Department of the Science Faculty). It targets universities and research centers involved in nuclear energy and is based on ongoing partnerships with CFA EpureMéditerranée (apprenticeship center), EDF, and CEA thanks to on a solid research background in the LIMMEX laboratory run jointly by CEA and AMU (IM2NP) and dedicated to Instrumentation and Measurements under EXtreme conditions, on the ANIMMA international conference and the EFMMIN Franco-Moroccan school. This has led to the development of a useful network of operators (partners involved in the project) in priority geographical areas for AMU's international strategy: Nuclear Reactor Laboratory at MIT, Moroccan Nuclear Center and Mohammed V University, Polish Nuclear Center, Slovenian Jožef Stefan Institute, Belgian Nuclear Center. The project will consist in sending a group of block-release apprentices for one week per year to a partner site who will propose visits to reactors, laboratories and companies, and participation in seminars, short courses, experimental projects and workshops together with local students. They will visit cultural places and prepare an activity report in English. When the project is completed its possible extension to other block-release courses at AMU will be examined because international mobility is a real advantage in terms of employability for young-people.
\end{abstract}

Index Terms Mobility, Education, Nuclear Energy, Research Reactor, Instrumentation.

\section{INTRODUCTION AND AIMS}

- irst of all, the MOBIL-APP project concerns the outgoing

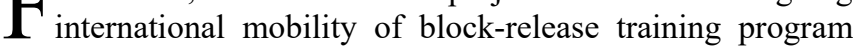
apprentices preparing the Master's degree belonging to the "Filière Instrumentation" unit of the Physics Department of the Faculty of Sciences. The "Filière Instrumentation" was created in 1985 by AMU with the collaboration of the national nuclear agency CEA and industrial firms of South-East France.

This unit offers training courses in industrial R\&D instrumentation, automation, testing means, process control and metrology. It has two main objectives: (1) to provide high-level scientific and professional programs and (2) to meet industrial and economic needs. It proposes two accredited degrees (Vocational Bachelor's and Master's degree) and includes over 150 students a year. The Filière Instrumentation unit has been ISO 9001 certificated since 2003 for the design and provision of initial, continuing and block-release training programs and the accreditation of prior experiential learning for all its training programs. Consequently, the courses may be taken in various ways: initial, continuing and block-release training programs, and the accreditation of prior experiential learning.

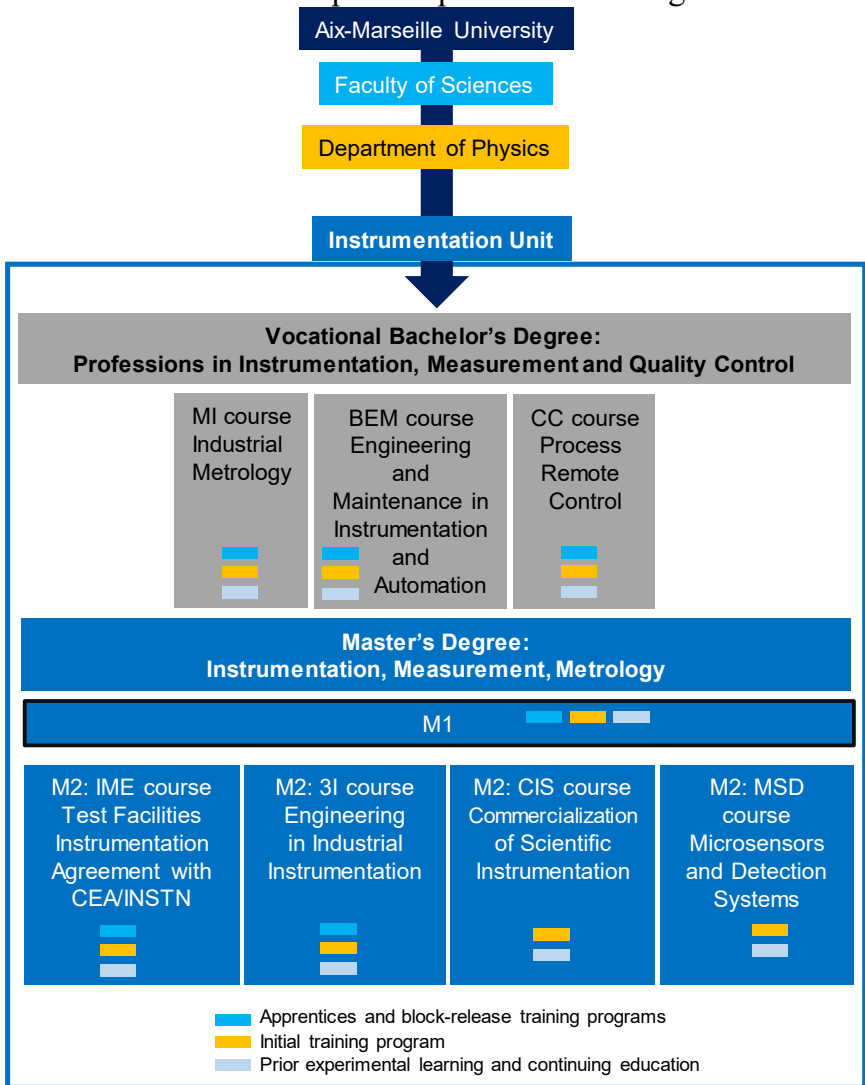

Fig. 1. Diagram of the degrees of the Instrumentation Unit ("Filière Instrumentation")

The MOBIL-APP project concerns the block-release training programs mainly with apprentices, but also with some students in the continuing program.

For students enrolled in this kind of block-release program (apprentice or continuing status), it is very difficult to take advantage of usual international mobility schemes for long periods. This is due to the specificities of the block-release schedule. Students enrolled in such programs must share periods between university and workplace as opposed to those in an initial program with long periods available for uninterrupted internship. In the case of our block-release students in M1 and M2, they begin with one month at university with the more fundamental courses. Then they pursue a period alternating every 2 weeks between their company and the university. Finally, they spend 1.5 months in the company 
during summer before defending their master's degree report on their activities there (cf. Fig.1). Our initial-program students in M1 and M2, however, have a 7-month period at university followed by a long continuous period devoted to their internship. The duration of the internship is from 3 to 6 months depending on the program year. The internship or the company alternation periods constitute a large education unit accounting for the most ECTS credits (12) in a year. In France, 43000 students accessed international mobility in 2017 as against 6 800 apprentices, for whom the duration was only from 2 to 4 weeks. Since 1987, 615000 French students have been involved the Erasmus program as against 25600 apprentices [1-2]. Students who choose the apprentice status often do so to receive a salary in order to finance their studies, and yet do not have an equal opportunity for international mobility with regard to students enrolled in initial training programs.

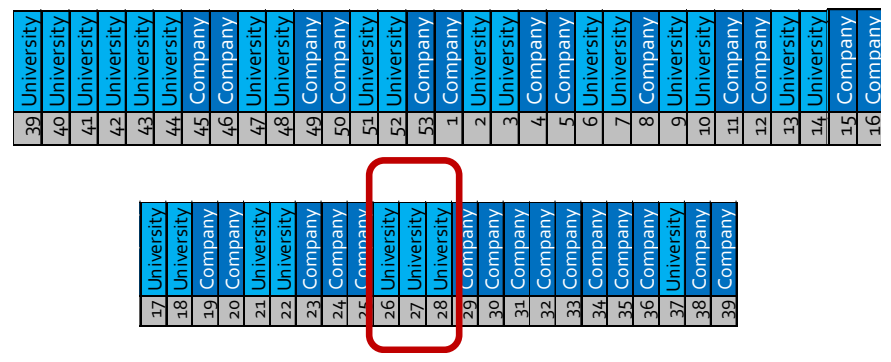

Fig. 2. Diagram of apprenticeship period schedule

Consequently, specific actions are required for apprentice students in order to increase their opportunities for outgoing international mobility as this is a crucial factor with various advantages. This is the aim of the MOBIL-APP project.

For instance, international mobility is a strong point on the curriculum vitae of alumni beginning their young professional career either in French companies with international activities or in international companies. It also provides the opportunity to practice English in real conditions. Students can gain in personal autonomy and acquire cultural experience. They can discover other educational systems. They can develop their capacity to adapt. All of which demonstrates the dynamism of the student in his CV. Moreover, outgoing international mobility performed in an academic environment with a high level of research activities can stimulate new vocations in the field of research for young students and thus a project for a $\mathrm{PhD}$ thesis. As they mainly work in industrial companies, few apprentices reach such an academic level, even if they have a capacity for hard work, possess organizational, scientific and technical skills, and obtain good academic results.

Furthermore, the project concerns the outgoing international mobility of apprentices with partners involved in a key field: the nuclear energy field. Nuclear energy field corresponds to an important job source [3]. It constitutes a major component of the energy mix and is in particular a recognized asset in terms of the reduction of greenhouse gas emissions. Nuclear energy could be a sustainable source of energy thanks in particular to continuous research and development on material and fuel behavior. The development and qualification of materials/fuels with relevant conditions for nuclear power plants contribute to the optimization and the demonstration of the safe operating of existing and upcoming nuclear power reactors - Generations II and III - (plant life extension and management, reinforcement of safety, waste and resource management, economic improvement), as well as the support for future generations of nuclear reactor design such as Generation IV reactors (improvement of the use of uranium resources and reduction of long-lived radioactive wastes).

Moreover, at present, major international nuclear fission and fusion facilities are under construction in the south of France (Cadarache area) such as the Jules Horowitz Reactor (JHR) and ITER.

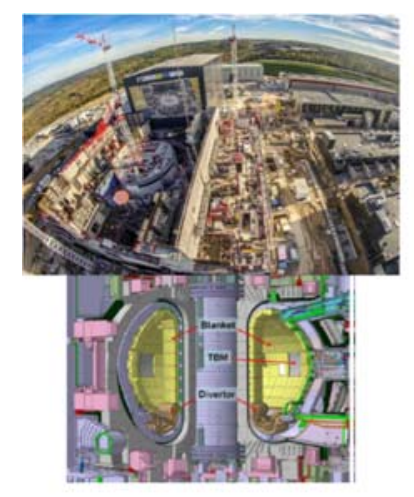

ITER

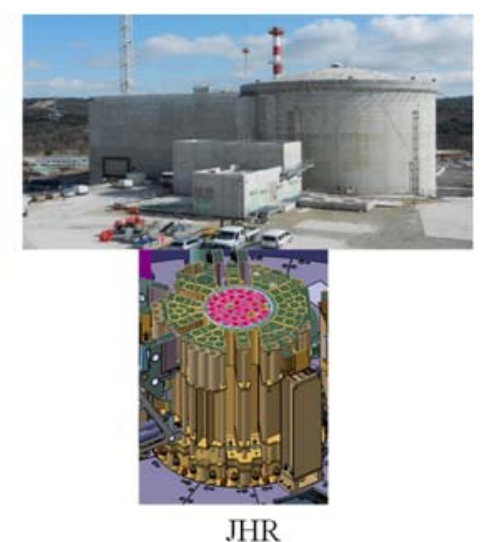

JHR
Fig. 3. Photographs of major nuclear facilities under construction in the south of France

For instance, we can focus on the case of nuclear fission and of Material Testing Reactors (MTR) which offer the widest experimental capacity to study materials (accelerated ageing) and fuels under irradiation conditions (but also medical radioisotope and doped silicon carbide production). As all European Material Testing Reactors are over 40 years old and will be shut down in the next few years (for instance, the shutdown in 2016 of the only French MTR called OSIRIS near PARIS), the new JHR MTR is currently under construction at the CEA Cadarache. This new flexible experimental infrastructure will offer modern experimental capabilities with innovative on-line instrumentation, possess huge capacities with high performance and versatility, and provide harsher nuclear conditions. It involves an international consortium with various members (CIEMAT (Spain), SCK (Belgium), CVR (Czech Republic), VTT (Finland), IAEC (Israel), DAE (India), NNL (United Kingdom), STUDSVIK (Sweden), CEA, EDF and AREVA (France), JAEA (Japan)). It will be started up in 2022-2023.

Consequently, the MOBIL-APP project will target high-level international partners possessing specific nuclear facilities (in the USA, Europe and Mediterranean) in order to prepare students for present and future needs in the nuclear energy field while at the same time major research infrastructures now under construction require experts and young graduates with specific scientific and technological skills and international capacities.

As other European projects, such as the ENEN + project [4], the MOBIL-APP project aims to interest students for the nuclear field, to attract talents to careers in this field and to develop specific skills. 


\section{Project Characteristics}

\section{A. Partners and Funding}

This project obtains a funding for two university years (20182020) from AMIDEX (Aix-Marseille University's foundation) in the framework of its Academy of Excellence program and from the CFA Epure Méditerranée.

The MOBIL-APP project involves:

\section{$\checkmark$ Two laboratories:}

- IM2NP laboratory (UMR 7334), Detection department, Microsensors and Instrumentation research team,

- $\quad$ LIMMEX laboratory (laboratory run jointly by the CEA and AMU) dedicated to Instrumentation and Measurements under EXtreme conditions.

$\checkmark$ And various partners:

- French partners such as the CFA Epure-Méditerranée (apprentice center), EDF and the CEA,

- International partners: Nuclear Reactor Laboratory at MIT (NRL, USA), Moroccan Nuclear Center (CNESTEN), Polish Nuclear Center (NCBJ), Jožef Stefan Institute (Slovenia), Belgian Nuclear Center (SCK-CEN)).

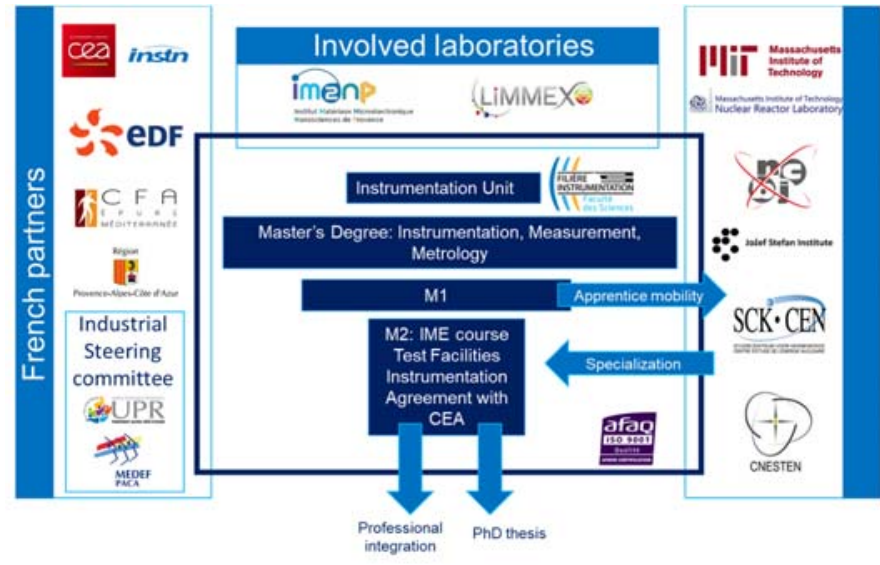

Fig. 4. Diagram of the MOBIL-APP project consortium

These partners were chosen and contacted because (except for the CFA) they are major research or industrial players in the nuclear energy sector or emergent player. They are involved in high level research works or research and development activities. They possess different and interesting kinds of nuclear facilities requiring dedicated instrumentation and measurement methods:

$\checkmark$ CEA Cadarache: for instance the CABRI Reactor (pool type research reactor dedicated to fast power transients and therefore to simulating a reactivity insertion accident in a PWR electricity-generating reactor), JHR under construction (Material Testing Reactor, 100MWth), WEST Tokamak (Fusion Tokamak with actively cooled tungsten divertor), RES (research testing reactor for nuclear naval propulsion), and MASURCA (critical facility, zero power research reactor $5 \mathrm{kWth}$ )

$\checkmark$ MIT: MIT-R, a pool type research reactor (6MWth) containing in-core experiment facilities and an instrumented water loop $\checkmark$ NCBJ: MARIA, a Material Testing Reactor (24MWth)

$\checkmark$ SCK-CEN: BR2, a High Flux Material Testing Reactor (100MWth) and BR1 for research in reactor and neutron physics (700kWth)

$\checkmark$ JSI and CNESTEN: TRIGA reactor (250kWth)

$\checkmark$ EDF: Nuclear Power Plants from Gen II to Gen III

The CFA is involved in this project because it is an interuniversity (4 universities) center for the Region of Provence-Alpes-Côte d'Azur (PACA) dedicated to:

- Promoting and developing block-release training programs at university

- Improving the employability of young diploma holders

- Harmonizing the regional offer of university level apprenticeship training

The CFA is already involved in international mobility for apprentices belonging to engineering schools (in which case mobility is required in order to obtain the engineering diploma). Consequently, the CFA helps us especially at the administrative and regulatory level with the feedback from its experience with such diplomas.

B. Master's degree in Instrumentation, Measurement and Metrology

The Master's degree involved in the MOBIL-APP project is entitled Instrumentation, Measurement and Metrology and is composed of four specialities dedicated to Engineering, Test Facilities, Microsystems and Commercialization respectively (cf. Fig. 1). The project concerns the IME course on test facilities instrumentation. It was developed in collaboration with the CEA in 2004. It is now a diploma co-delivered by AMU and the national nuclear science and technology institute of CEA (INSTN). This training course comprises $545 \mathrm{hrs}$ in the first year (or level M1) and 710 hrs in the second (M2). Each level is divided into several education units and comprises 60 ECTS credits. M1 is a common course year whatever the course chosen in M2. The IME course offers a specialisation in Nuclear Detection and Instrumentation. Currently this specialisation is obtained on the basis of preliminary courses in M1, a whole education unit in M2, partial education units in M2 and activities in a laboratory or company in M1 and M2. Teachers involved in this specialisation are mainly CEA researchers and research engineers, and teacher-researchers of the university belonging to the LIMMEX Laboratory and IM2NP Laboratory. This course (M1, M2) may be taken in various ways: initial, continuing and block-release training programs, and the accreditation of prior experiential learning.

\section{Promotion 2018-2019}

The project for the first mobility period realized this university year (2018-2019) consists in three phases corresponding to:

$\checkmark$ The selection of the apprentices students and their preparation

$\checkmark \quad$ The mobility period for a group of selected students for 1 week in a partner

$\checkmark$ The assessment

The two partners hosting the two groups of students were the Nuclear Reactor Laboratory of the MIT (USA) and the NCBJ (Poland). 
1) First step: selection and preparation in France

The selection is realized thanks to

$\checkmark$ Different documents provided by students by respecting imperatively deadlines (a covering letter, a questionnaire in French and in English)

$\checkmark$ A personal interview

$\checkmark$ Academic results and English level

$\checkmark$ Career project

For 2018-2019, the selection concerned 16 students out of 30 (8 for NRL mobility, 8 for NCBJ mobility). These selected students belong to several companies in different fields: ARCELORMITTAL, ARTELIA, CEA, CSTB, INEO NUCLEAIRE, IPSEN PHARMA BIOTECH, JTEKT AUTOMOTIVE LYON, M3E, PRECITEC, SECAUTO, SEMATEC METROLOGIE, TECHNICATOME.

The preparation for these 16 students consisted in:

$\checkmark$ An Education Unit dedicated to an introduction to Research with international bibliographical works on Nuclear Detection and Instrumentation, then to the realization of a poster on selected topics (sensors, reactor specificities) and then a presentation associated to this poster (10.5 hours),

$\checkmark$ Courses in scientific and technological communication, each student in particular having to prepare and give a talk presenting his/her educational background, company activities and professional responsibilities in English (14 hours)

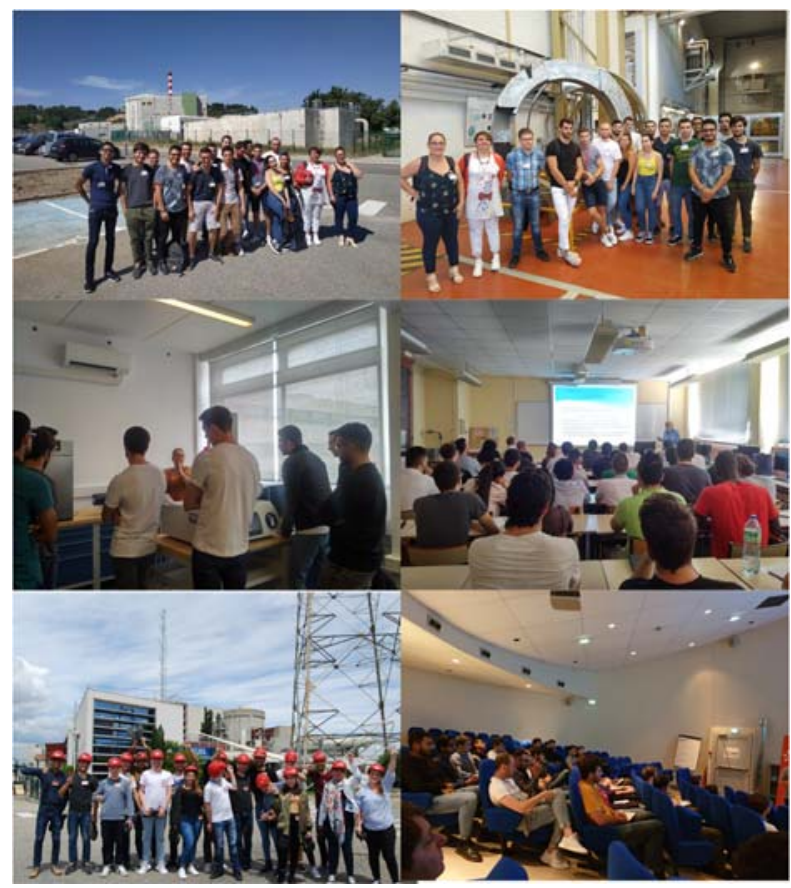

Fig. 5. Photographs associated to the preparation step in France

$\checkmark$ Different visits: a visit to Cadarache CEA Center, a visit to LIMMEX Laboratory (in particular research activities and associated experimental devices/benches dedicated to nuclear absorbed dose rate measurements by means of calorimeter in MTRs [5-8]) and a visit to EDF Company (Tricastin Power Plant) $\checkmark$ Talks given by representatives of EDF, the CEA (in particular talk dedicated to the Jules Horowitz Reactor) and the University

$\checkmark$ Seminar with a scientist working on nuclear detection by means of semiconductors

\section{2) Second step: mobility period}

The mobility period consists in intense short stay (7 days). Each student-group is accompanied by two teachers-researchers belonging to the supervising and teaching team.

For 2018-2019, it included different activities:

$\checkmark$ Partner talks for presenting their research activities and their reactor (MITR-II in USA and MARIA in Poland)

$\checkmark \quad$ Visits to reactors and associated laboratories

$\checkmark$ Short courses and experimental projects (nuclear detection, communication, reactor control, gamma spectrometry)

$\checkmark$ Seminars performed by students for presenting their academic cursus, their companies and their professional activities

$\checkmark$ Visits to organisms and companies (Mirion Technologies (Canberra) Inc and RMD Inc in USA, POLATOM and The Maria Skłodowska Curie Memorial Cancer Centre and Institute of Oncology in Poland)

$\checkmark \quad$ Visits to university campus and museums

$\checkmark \quad$ Visits to other cultural places

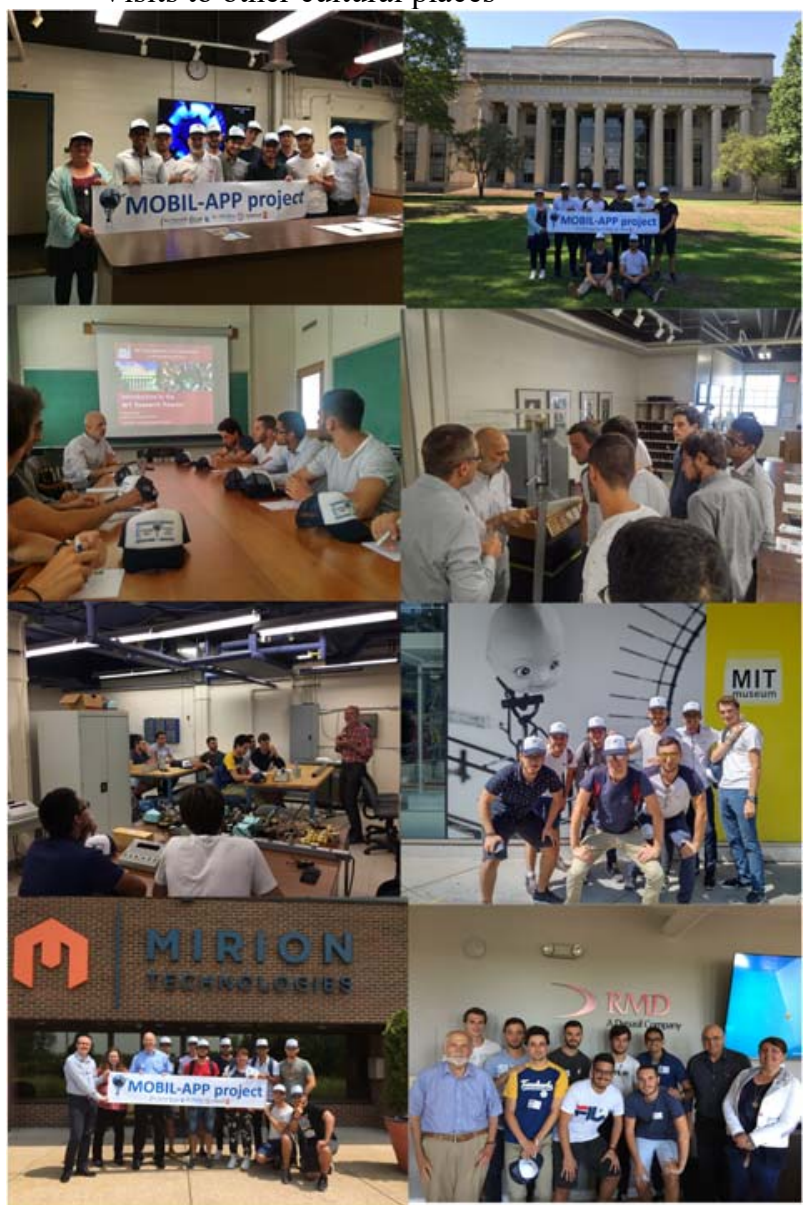

Fig. 6. Photographs associated to the mobility period in USA 


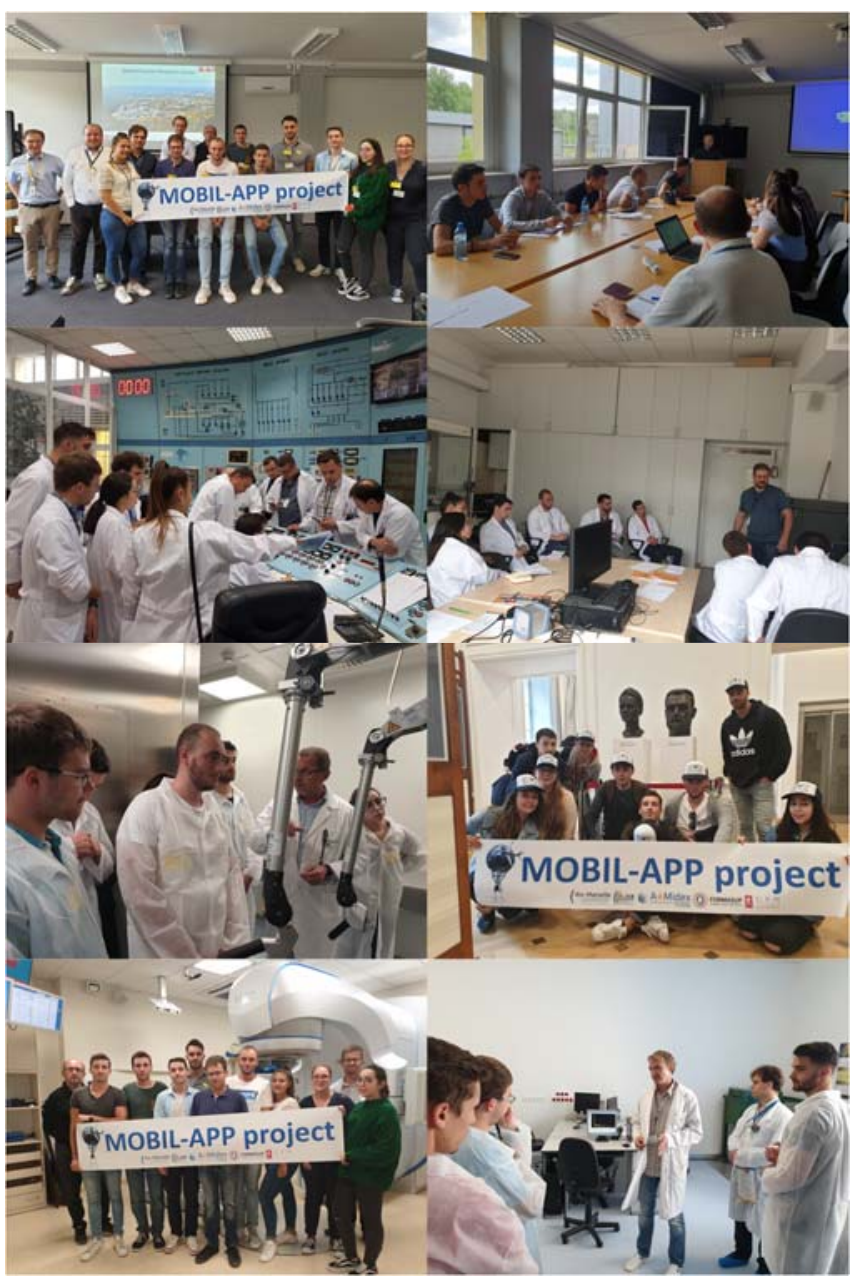

Fig. 7. Photographs associated to the mobility period in Poland

\section{3) Third step: assessment}

The supervising team will assess the mobility of each student by different means.

Each student will prepare an activity report in English including technical, scientific and cultural aspects.

Then student feedback will be done in various ways. A first assessment will be carried out just after their stay. A specific questionnaire will be delivered to each student with a $100 \%$ return targeted. Each student's degree of satisfaction concerning different points will thus be assessed: the duration and location of the mobility, organization, preliminary steps in Marseille, hosting partner, supervising team, training activities (seminar, short courses, facility visits), new skills acquired, enhancement of English level, other activities (cultural visits), impact on the professional/personal project.

Other assessments will be made during our surveys to establish the number of alumni who have become economically active 6 and 18 months after graduation (individual interview by phone). Questions will be added on their professional activity (advantage of mobility in finding a job or a thesis, international company or activities, job in or for the nuclear sector, opinion after several months about the international mobility experience), impact of the mobility period after a few months on the student's professional project and on the professional integration rate of diploma holders).

\section{Conclusions}

The MOBIL-APP project corresponds to a real opportunity for selected students (apprentices) enrolled in the block-release training program associated to the Master's degree in Instrumentation, Measurement, Metrology of Aix-Marseille University. An international mobility period owns various advantages inducing new soft and hard skills for each students that can be useful for their career. Moreover, as the international mobility is organized in the nuclear energy field, this mobility could confirm or generate a professional vocation in this field. The preliminary assessment for the first class will be realized before the end of September. The obtained output data will contribute to the enhancement of the second mobility period which will be done in June 2020 with two new groups of students.

\section{ACKNOWLEDGEMENTS}

The MOBIL-APP project leading to this publication has received funding from Excellence Initiative of Aix-Marseille University - A*MIDEX, a French "Investissements d'Avenir" programme.

\section{REFERENCES}

[1] http://travail-emploi.gouv.fr/actualites/l-actualite-duministere/article/decryptage-5-cles-possibles-pour-davantagede-mobilite-des-apprentis-en-erasmus

[2] S. Brunet, Report « le développement de l'apprentissage », January 2018.

[3] L. Parizot, Report «plan de programmation des emplois et des compétences », February 2019.

[4] https://plus.enen.eu/

[5] A. Volte, C. Reynard-Carette, A. Lyoussi, J. Brun, and M. Carette. Study of the Response of a New Compact Calorimetric Cell for Nuclear Heating Rate Measurements, IEEE TNS, Volume: 65, Issue: 9, Sept. 2018, Page(s): $2461-2470$.

[6] Michel Giot, Ludo Vermeeren, Abdallah Lyoussi, Christelle Reynard Carette, Christian Lhuillier, Patrice Megret, Frank Deconinck, Bruno Soares Goncalves, Nuclear instrumentation and measurement: a review based on the ANIMMA conferences, EPJ Nuclear Sci. Technol. 3, 33 (2017) 49 pages. [7] J. Brun, M. Tarchalski, C. Reynard-Carette, K. Pytel, A. Lyoussi, J. Jagielski, D. Fourmentel, J-F. Villard, M. Carette, Responses of Single-Cell and Differential Calorimeters: from Out-of-Pile Calibration to Irradiation Campaigns, IEEE Transactions on Nuclear Science, Vol. 63, NO. 3, June 2016, $1630-1639$

[8] C. Reynard-Carette, G. Kohse, J. Brun, C. Carette, A. Volte, A. Lyoussi, Review Of Nuclear Heating Measurement By Calorimetry In France And USA, EPJ Web of Conferences 170, 04019 (2018) 